ClassifiedAdOrderBlank

Infection Control \&

H ospital E pidemiology

Classified Marketplace

SLACK Incorporated

6900 Grove Road

Thorofare, New Jersey 08086

Advertiser or Agency, please complete the following:

(Noncommissionable)

\section{SEND INVOICE TO:}

Name

Address

City —State____ip

Telephone

Please insert the following typewritten ad- $\mathrm{t}$ i m e ( $\mathrm{s})$ beginning with the next available issues.

(Check box to indicate category)'

$\square$ Employment Opportunities $\square$ For Rent

0 Positions Wanted 0 Meetings

0 Educational Opportunities 0 Wanted

0 Services 0 Miscellaneous

0 For Sale

\title{
Classified Marketplace
}

\section{EMPLOYMENT OPPORTUNITIES}

INFECTION CONTROL PRACTITIONER: Immediate opening for experienced ICP in dynamic Infection Control Program in the Infectious Disease Division of Winthrop-University Hospital on Long Island, NY. Winthrop-University Hospital is a 600-bed teaching hospital affiliated with SUNY School of Medicine at Stony Brook. Great opportunity for an academically inclined ICP. Send CV in confidence to Burke A. Cunha, M.D., Chief, infectious Disease Division, Winthrop-University Hospital, 259 First Street, Mineola, NY 11501.

\section{SERVICES}

A FAX MACHINE IS AVAILABLE for your convenience. FAX YOUR CLASSIFIED AD TODAY for placement in the next available issue of Infection Control \& Hospital Epidemiology Classified Marketplace (609) 853-5991.

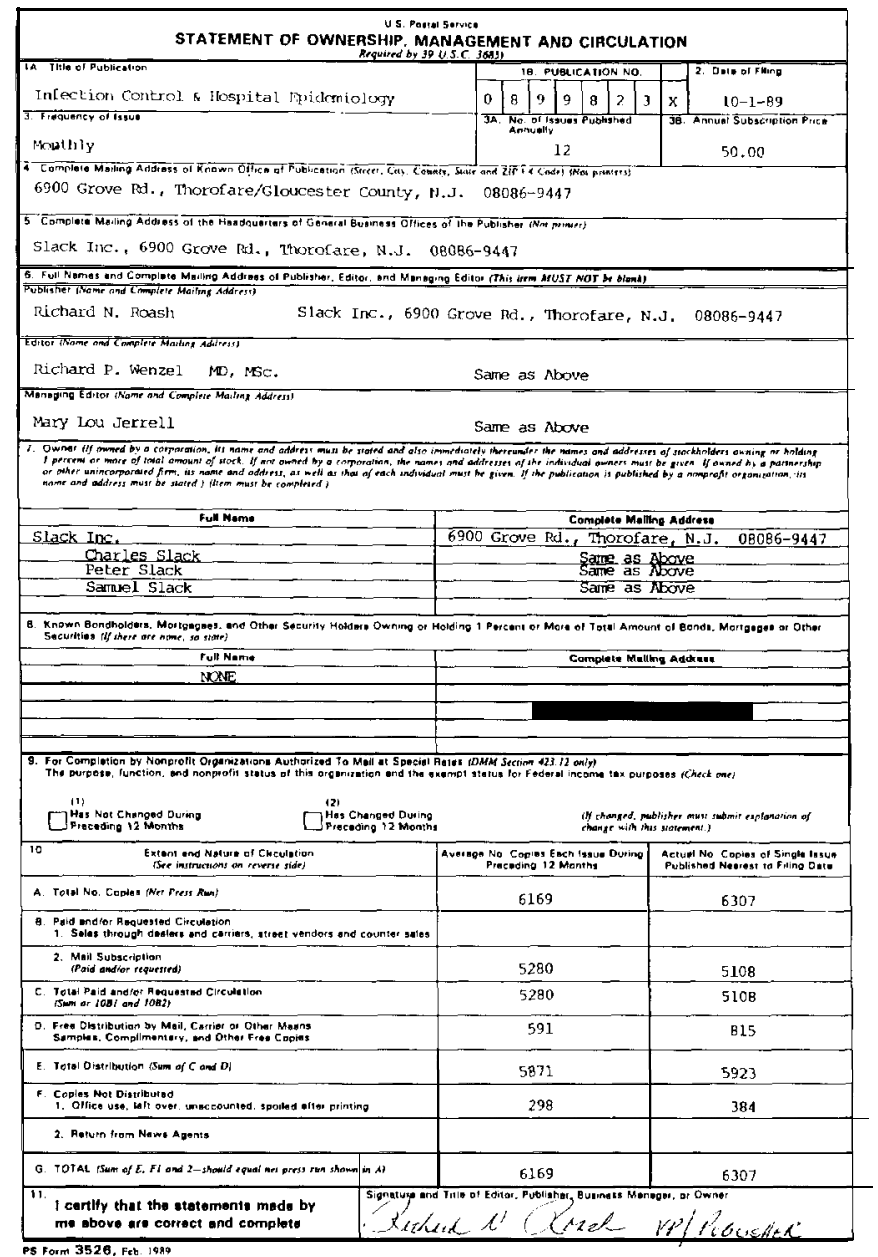



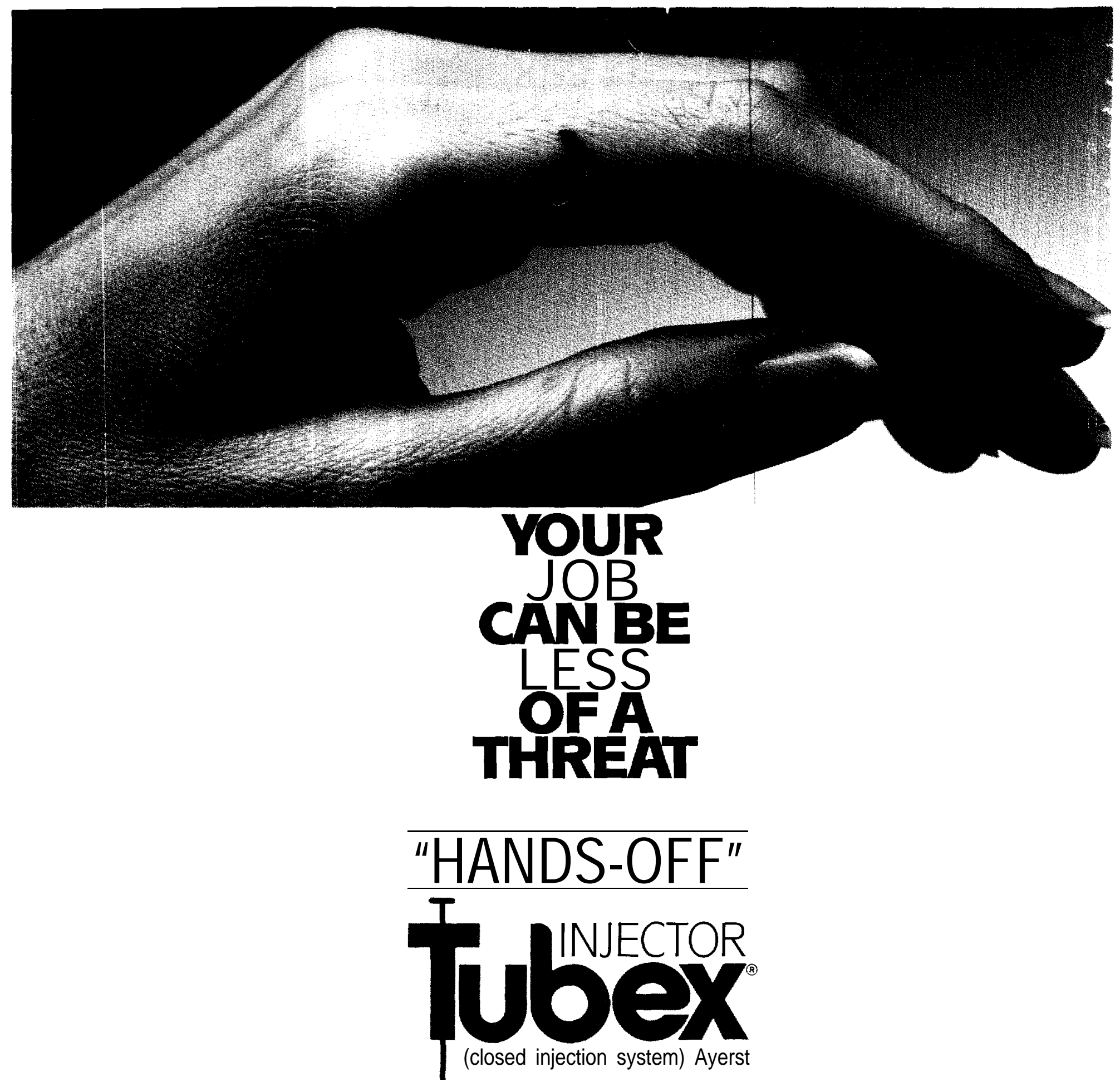

TUBEX? the unique, safer, hands-off. injector that puts you farther from the needle and cartridge than any other injection system.

There's no touching.. shaking... manipulation of cartridge or needle. Just twist and drop.

Nurses preferred TUBEX almost $3: 1$ for the prevention of accidental needle stick injuries in a study comparing TUBEX Injector and Carpuject $t^{* * 1}$ Which is one more reason to

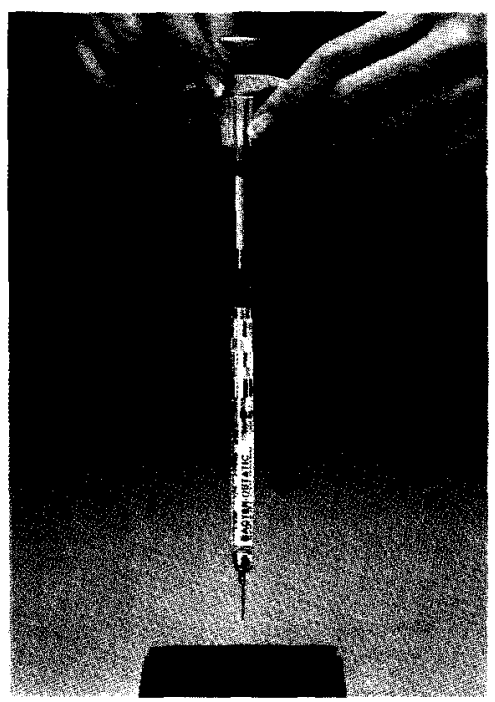

adopt TUBEX- the injection system designed as if your life depended on it.

\section{FARTHER FROM THE POINT OF DANGER}

1 Data on file Ayerst Laboratories 7 WYETH-AYERST

II LABORATORIES

Philadelphia, PA 19101 01989. Ayerst Laboratories. 54667 